\title{
Influence of Treatments for Depression and Sleep Quality on Heart Rate and Blood Pressure in Individuals with Hypertension and Depression
}

\author{
Marcello Finardi Peixoto*, Mario Luis Ribeiro Cesaretti, Agostinho Tavares \\ Internal Medicine Department, Nephrology Section Federal University of São Paulo, São Paulo, Brazil \\ Email: marcello.fp@uol.com.br
}

Received 1 April 2015; accepted 24 May 2015; published 27 May 2015

Copyright (C) 2015 by authors and Scientific Research Publishing Inc. This work is licensed under the Creative Commons Attribution International License (CC BY). http://creativecommons.org/licenses/by/4.0/

\section{(c) (i) Open Access}

\section{Abstract}

Objective: To observe the influence of the treatment of depression on the regularization of blood pressure and heart rate of individuals with hypertension and depression. Methods: A total of 30 individuals who were being treated for hypertension were diagnosed for depression participated in this study. Escitalopram (10 - $20 \mathrm{mg}$ ) was administered to 15 individuals, while the other 15 received placebo. These individuals were followed for 8 weeks with regular monitoring of blood pressure and heart rate. Scores on the Hamilton Depression Rating Scale were evaluated within the first, second, fourth, and eighth weeks of the study onset. The same 30 individuals were further divided into groups who had or had not undergone depression remission, regardless of whether the individual was receiving the active drug or placebo. Likewise, in order to observe the influence of sleep regularization, the patients were divided into groups based on whether their sleep quality had improved. Results: There was a significant decrease in the average systolic blood pressure of the normal-sleep group $(-20.07 \pm 13.45$ vs. $-9.43 \pm 14.87 \mathrm{mmHg}, p=0.04)$. Heart rate was lower in the escitalopram than in the placebo group: $66.88 \pm 9.62$ vs. $74.19 \pm 9.55$ bpm, $p=0.04$. Conclusion: Treatment with escitalopram decreased heart rate, improved sleep quality, and decreased blood pressure.

\section{Keywords}

Hypertension, Heart Rate, Depression, Escitalopram, Sleep, Anxiety

\footnotetext{
${ }^{*}$ Corresponding author.
} 


\section{Introduction}

Depression and cardiovascular disease are the two leading causes of disability worldwide and are among the five most frequent chronic diseases in elderly patients [1].

Numerous studies suggest that depression or depressive symptoms that do not meet the criteria for major depressive disorder are risk factors for cardiovascular disease in healthy subjects [2], recurrence of pre-existing cardiovascular events [3] [4], and worse prognosis after revascularization of the coronary arteries [5].

Data from 30,801 adults in the "National Health Survey [6]" showed that annually depressive disorder was prevalent in $4.8 \%$ of the American population as a whole. Among individuals with systemic hypertension (SH), this prevalence rises to $8 \%$ with a relative risk of 2.00. Adamis and Ball [7], as well as Nakagawara [8], described the increased prevalence of hypertension in patients with depression.

In Brazil, Amaral et al. [9] found that major depressive disorder was prevalent in $20 \%$ of outpatients from a university referral center for hypertension. Moreover, Benseñor et al. [10] observed a prevalence of 58.5\% in other clinics that specialized in hypertension.

Another prospective study suggested that depression should be a risk factor for development of hypertension. Jonas et al. [11] evaluated a cohort of 2992 men and normotensive women through the "National Health and Nutrition Examination Epidemiologic I Follow-Up Study", which lasted 7 - 16 years. Incident hypertension was defined when patient blood pressure (BP) was $\geq 160 / 95 \mathrm{mmHg}$. In this cohort, higher scores of anxiety and depression were independent predictors of incident hypertension in white individuals aged 45 - 64 years.

Rabkin et al. [12] studied 452 outpatients; the diagnosis of major depression according to the Diagnostic and Statistical Manual of Mental Disorders (DSM) III was three times more common among individuals with hypertension than those without. This was true even after correcting for age, sex, chronic medical illness, and current use of antihypertensive medication.

Hopelessness, one of the clinical features of depression, is also associated with a higher incidence of hypertension. Everson et al. [13] followed 616 normotensive men from Eastern Finland, aged 42 - 60 years, for 4 years. Hopelessness was measured by two items that assessed negative expectations about the future and personal goals; individuals with higher scores of hopelessness at baseline were three times more likely to become hypertensive.

Poulter et al. [14] analyzed the effect of migration, a life event known to cause stress. A group of 63 individuals who migrated from rural to urban Kenya, and 143 controls who continued to live in rural areas were followed for 24 months. The Kenyan population is known to have lower BP $(120 \times 60 \mathrm{mmHg})$. The mean systolic $\mathrm{BP}$ of the migrant group was significantly higher than that of the controls. The weight and heart rate (HR) were also higher in migrants. HR variation also appeared to be associated with stressful events. In addition, the urinary sodium/potassium ratio was higher in migrants, indicating a diet change influenced BP oscillation.

Regarding the physiological mechanism inherent to both depression and hypertension, it probably involves the sympathetic nervous system, hypothalamus-pituitary-adrenal (HPA) axis, and renin-angiotensin-aldosterone (RAA).

The role of the SNS is well established in hypertension. In summary, it is known that the SNS, via the release of norepinephrine (NE), acts on betal receptors in the juxtaglomerular apparatus increasing renin levels, on alfa1B receptors in the tubules, resulting in decreased sodium excretion, and on alpha1 $\mathrm{A}$ in renal artery, causing decreased renal blood flow and a decreased glomerular filtration rate [15]. A lot of evidence points to the involvement of the SNS in depression. Briefly, in patients with depression, NE and metabolite of NE (MHPG), levels increase in the cerebrospinal fluid (CSF) and urine. Individuals with depression also exhibit increased baseline levels of plasma NE, as well as attenuated response to alpha2 agonists, growth hormone, and increased density activation of platelets alpha2. Moreover, antidepressants whose biochemical effects include increasing NE have proved effective in treating depression, while the reduction of NE metabolism (turnover) has shown to be an efficient antidepressant treatment.

With regard to the involvement of the HPA axis, patients with depression have been found to exhibit increased corticotropin-releasing factor $(\mathrm{CRF})$ in the CSF and an attenuated response of the adrenocorticotropic hormone (ACTH) to stimulation by CRF. Reduced CRF receptor levels have been in the frontal cortex of individuals who have attempted suicide in post-mortem studies. Patients with depression often exhibit increased pituitary and adrenal glands activity, as well as increased cortisol production during a depressive episode. In addition, they display non-suppression during the dexamethasone suppression test, and increased urinary free-corti- 
sol concentrations. CRF agonists have been shown to elicit depressogenic behavioral and anxiogenic effects. Moreover, CRF receptor antagonists and glucocorticoid blockers have both proved effective in treatment of depression [16]. In the cardiovascular system, cortisol potentiates the vasoconstrictor effects of catecholamines, which is important for maintaining vascular tone. In addition, glucocorticoids enhance the effects of angioten$\sin -2$ and reduce the vasodilatory effects of nitric oxide in the endothelium [17].

The first evidence that the renin-angiotensin (RAA) system plays an important role in depression came with the observation that captopril induced an antidepressant effect in hypertensive rats that suffered from depression [18] [19]. Furthermore, the antidepressants fluoxetine, desipramine, and tranylcypromine are known to reduce dipsogenicity induced by angiotensin-2 [20]. Pretreatment with captopril reduces immobility in the forced swim test, which is an animal model of depression; this effect is equivalent to pre-treatment with the antidepressants, imipramine and mianserine [21]. Additionally, captopril administration proved as effective as imipramine in an animal model of learned helplessness [22]. In other studies, high levels of aldosterone were found in a sample of patients who met the criteria for depressive disorder, compared with controls matched for age and sex. Renin levels were also likely to increase, although this particular finding was not significant [23] [24].

Obstructive sleep apnea seems related to both diseases. In the United States, data from the "National Ambulatory Medical Care Survey" and "National Hospital Ambulatory Medical Care Survey" (2008 to 2009) reported 4.1 million outpatient visits with this primary diagnosis. Among patients with obstructive sleep apnea, there was a $23.2 \%$ comorbidity rate for depression and $53.8 \%$ for hypertension. Moreover, the odds ratio (OR) for depression was $2.5[25]$.

It is also known that individuals with depression are more sedentary, less adherent to medications, less able to change their lifestyle, and more likely to smoke and abuse alcohol [26] [27]. These habits are also risk factors for hypertension.

Therefore, there is a lot of evidence that depression influences both SH and HR.

\section{Objectives}

Primary: To assess whether the use of escitalopram influenced blood pressure and heart rate levels in patients (treated and depressed) with stage 1 or 2 hypertension.

Secondary: To assess whether the remission of depression influenced the blood pressure and heart rate of patients (treated and depressed) with stage 1 or 2 hypertension.

Tertiary: To assess whether regularization of sleep influenced the blood pressure and heart rate of patients (treated and depressed) with stage 1 or 2 hypertension.

\section{Materials and Methods}

Figure 1 shows the chronological sequence of procedures and visits established by the study protocol, which will be detailed in the summary of the study protocol.

\subsection{Summary of Study Protocol (Figure 1)}

At time 0, patients in the hypertension clinic of the Department of Nephrology (UNIFESP) were selected according to inclusion and exclusion criteria. Selected patients underwent a complete physical examination; the Self-Report Questionnaire (SRQ 20) and Structured Clinical Interview for DSM-IV (SCID) tests were administered for diagnosis of depression. At this time, anti-hypertensive drugs were suspended ("Wash-out") and lifestyle changes were recommended [28].

At time 1, after 2 weeks from time 0 , a physical exam was performed and the presence of hypertension (stages 1 or 2) was confirmed. At this time point, the Hamilton Depression Rating Scale (HAM-D) was applied to assess the intensity of depression and sleep quality. Finally, patients who met the criteria were randomized to groups that either received $10 \mathrm{mg}$ of escitalopram or placebo. All received losartan/hydrochlorothiazide 50/12.5 mg.

Time 2, after another 2 weeks, patients underwent a complete physical examination and the HAM-D test was conducted to evaluate the scores of depression.

At time 3, in the sixth week of the protocol, a physical examination and evaluation of the depressive state was conducted, and escitalopram or placebo doses were scaled up to two capsules/day for non-respondent patients.

Finally, at time 4, the tenth week of the protocol, the investigator again performed the complete physical ex- 


\begin{tabular}{|c|c|c|c|c|}
\hline $\begin{array}{l}\text { Start Date } \\
\text { Time } 0\end{array}$ & $\begin{array}{l}\text { Week } 2 \\
\text { Time } 1\end{array}$ & 4th week Time 2 & 6th week Time 3 & 10th week Time 4 \\
\hline $\begin{array}{l}\text { SRQ 20-Screening } \\
\text { SCID-Depression diagnosis } \\
\text { BMI, smoking, alcohol, } \\
\text { exercise, ACO } \\
\text { HR and BP } \\
\text { Wash out anti-hypertensive } \\
\text { Guidelines lifestyle changes }\end{array}$ & $\begin{array}{l}\text { BP, HR } \\
\text { HAM-D: score of depressive } \\
\text { symptoms } \\
\text { losartan/hydrochlorothiazide } \\
50 \mathrm{mg} / 12.5 \mathrm{mg} \\
1 \text { group } \mathrm{n}=15 \text {-Escitalopram } \\
10 \mathrm{mg} \\
1 \text { group } \mathrm{n}=15-1 \text { placebo pill }\end{array}$ & BP, HR, HAM-D & $\begin{array}{l}\text { BP, HR, HAM-D } \\
\text { Escitalopram } 20 \mathrm{mg} \text { or } \\
\text { placebo increase } \\
\text { if no response }\end{array}$ & $\begin{array}{l}\text { BP, HR, HAM-D } \\
\text { BMI, smoking, alcohol, } \\
\text { exercise, ACO }\end{array}$ \\
\hline
\end{tabular}

\section{Figure 1. Study protocol.}

amination and evaluation of depression through the HAM-D test.

\subsection{Population}

At baseline, time (t) 0 , patients of both sexes who followed routine outpatient care for hypertension treatment in the hypertension clinic at the Nephrology Discipline of the Federal University of São Paulo (UNIFESP) had their charts evaluated and selected (Figure 1). Those patients met the following criteria in the period from $6 / 3 / 2010$ to $21 / 11 / 2010$ :

1) Inclusion criteria:

- Age between 18 and 65 years;

- Hypertension stage 1: diastolic blood pressure (DBP) 90 - $99 \mathrm{mmHg}$ and/or systolic blood pressure (SBP) 140 - 159;

- Hypertension stage 2: DBP 100 - $109 \mathrm{mmHg}$ and/or PAS 160 - $179 \mathrm{mmHg}$;

- Depressive episode diagnosis.

2) Exclusion criteria:

- Presence of liver disease, congestive heart failure, chronic renal failure and/or acute myocardial infarctiondiseases or comorbidities that would prevent the patient to attend scheduled visits or might interfere with the metabolism of the study drug;

- Secondary hypertension;

- Use of psychotropic drugs;

- Psychotic disorder, alcohol abuse or illicit drugs, and/or risk of suicide-as in SCID scale [29] specified below.

Patients who agreed to participate in the study signed the Terms of Consent. This research project was approved by the Research Ethics Committee of the Federal University of São Paulo (UNIFESP-HSP), No. 1551/08. Registered in Brazil Platform, CAAE No. 31068214.5.0000.5505.

\subsection{Clinical and Demographic Data}

In the initial evaluation ( $\mathrm{t} 0$ ), we obtained the following clinical and demographic data through direct questioning, clinical examination, and chart review:

- Age-in years;

- Gender;

- Level of education-determined by the number of years of study; a level of 8 was set for elementary school graduates, 11 for the high school degrees, and 15 if the patient completed college;

- Job;

- Civil-State considering legal marriage as married and divorced as single;

- Number of chronic diseases-the medical records were reviewed and taken into account for other chronic diseases as well as for depressive disorder and hypertension, which were not an exclusion criteria;

- Antihypertensive quantity-recorded as in the medical records, a point was assigned when the patient used the standard dose of a given medication;

- Smoking-asked directly to the individual. A patient was considered as a nonsmoker if abstinent for more than 1 year. Evaluated at $t 1$ and 4 ;

- Use of oral contraceptives-evaluated at $\mathrm{t} 1$ and 4 ; 
- Physical inactivity-patients were questioned about their physical activity; inactivity was considered when activities were practiced less than twice a week. Evaluated at $\mathrm{t} 1$ and 4;

- Alcohol intake-this was evaluated by the number of drinks per week. A patient was excluded from the study if alcohol abuse was identified (judged to be more than five drinks per week) [30]. Evaluated at t1 and 4;

- Weight and height-weight was measured in kilograms, a Filizola-branded balance (maximum load of 150 $\mathrm{kg}$ ), and the height in meters with an anthropometric ruler with the balance;

- Body mass index (BMI) was calculated by dividing weight (in kilograms) by height squared (in meters) (31).

\subsection{Psychometric Scales}

In this study, the principal investigator administered the SRQ-20 [29], which has been validated in Portuguese to evaluate psycho-emotional disorders.

The application of the scale lasted for 15 minutes, and served to detect individuals with any mental disorder, including, panic disorder, bipolar disorder, or paranoid schizophrenia, without necessarily being affected by depressive disorders that were of interest to this study. A score of 7 out of a maximum of 20 was considered the cut-off point [31].

Patients screened by the SRQ-20 underwent SCID [32] to confirm whether they had depressive disorder. This scale is also validated in Portuguese and testing lasts for approximately 1 hour. This interview provided further evaluation and justified excluding other psycho-emotional disorders that were incompatible with this study, such as psychotic disorders, history of alcohol and/or other substances, and/or suicide risk. Also confirms depressive disorder.

After the selection of patients in the $2^{\text {nd }}$ week (t1), the HAM-D was used to measure the severity of depressive disorder and clinical outcomes using a standardized questionnaire. The HAM-D was also used for evaluations at times 2 to 4 .

The response to antidepressant treatment was defined as a decrease $\geq 50 \%$ of the initial score on the HAM-D scale, and remission was defined as a drop of $<60 \%$ of the HAM-D initial score as well as a final score of less than 9 [33].

To evaluate sleep quality, items 4, 5, and 6 of the HAM-D scale were considered; the higher the score obtained in the sum of these items, the worst the sleep pattern was rated. At the last time point [4], we estimated regularization of sleep when the HAM-D scale score was equal to 0 .

\subsection{BP and HR Measurement}

The determination of ambulatory BP was conducted as recommended by the VI Brazilian Guidelines of hypertension [29]. We used the digital semi-automatic sphygmomanometer, Microlife brand, BP3BT0-H model because of its recommendation by the Brazilian Society of Hypertension and to avoid subjectivism of the measure. Each determination was performed with the patient seated for at least 5 minutes. BP and HR were measured three consecutive times, and an average was calculated. These procedures were carried out after the interview and the application of scales for diagnosing depression.

\subsection{Randomization}

This study meets the characteristics of a prospective clinical study, placebo controlled, block randomized [34], and double-blind. The first 15 individuals were placed in Group A and received a container with 30 capsules, while the remaining 15 patients were allocated to group B and also received 30 capsules. At the end of the study, it was revealed that group A received the placebo, while group B received escitalopram.

The $10 \mathrm{mg}$ of escitalopram was placed into 000 -sized pills. Placebo capsules were the same size, shape, and color as escitalopram pills; however, they contained only the shell. Both the interviewer and patients were blinded to the study.

\subsection{Statistical Analysis}

\subsubsection{Primary Objective}

A Student's t-test was conducted between the two groups to analyze differences in the SBP at t0, t1, t2, t3 and t4; DBP at $\mathrm{t} 0, \mathrm{t} 1, \mathrm{t} 2, \mathrm{t} 3$ and $\mathrm{t} 4$; SBP difference between times 0 and 1 ( $\mathrm{t} 0-\mathrm{t} 1)$ and between times 1 and 4 ( $\mathrm{t} 4-\mathrm{t} 1)$; 
DBP difference between times 0 and $1(\mathrm{t} 0-\mathrm{t} 1)$ and between times 1 and $4(\mathrm{t} 4-\mathrm{t} 1)$.

As additional measures, HR at $\mathrm{t} 0, \mathrm{t} 1, \mathrm{t} 2$ and $\mathrm{t} 4$; HAM-D scores at $\mathrm{t} 1, \mathrm{t} 2, \mathrm{t} 3$ and $\mathrm{t} 4$; and the change in BMI between $\mathrm{t} 1$ and $\mathrm{t} 4$ were compared between the two groups using a Student's $\mathrm{t}$ test. A p-value equal to or less than 0.05 was considered significant.

\subsubsection{Secondary Objective}

The placebo and escitalopram were collected and separated again by the status of depression remission. Remission was defined as a decrease of $60 \%$ of the initial HAM-D score and final score of less than 9.

A Student's t-test was conducted between the two groups to analyze differences in the SBP at $\mathrm{t} 0, \mathrm{t} 1, \mathrm{t} 2, \mathrm{t} 3$ and $\mathrm{t} 4$; DBP at $\mathrm{t} 0, \mathrm{t} 1, \mathrm{t} 2$, $\mathrm{t} 3$ and $\mathrm{t} 4$; SBP difference between times 0 and 1 (t0-t1) and between times 1 and 4 ( $\mathrm{t} 4-\mathrm{t} 1$ ); DBP difference between times 0 and 1 (t0-t1) and between times 1 and 4 (t4-t1).

As additional measures, HR t0, t1, t2 and t4; the HAM-D score $\mathrm{t} 1, \mathrm{t} 2, \mathrm{t} 3$ and $\mathrm{t} 4$ and the change in BMI between $\mathrm{t} 1$ and $\mathrm{t} 4$, between the two groups were analyzed by Student's $\mathrm{t}$ test. $\mathrm{P} \leq 0.05$ was considered significant.

\subsubsection{Tertiary Goal}

Upon merging escitalopram and placebo groups, a further classification was made to evaluate the status of sleep. The new groups comprised of the normal sleep group that had variable sleep in $t 4$ equal to zero, and the sleepless group with sleep score at 4 greater or equal to 1 .

A Student's t-test was conducted between the two groups to analyze differences in the SBP at $\mathrm{t} 0, \mathrm{t} 1, \mathrm{t} 2, \mathrm{t} 3$ and $\mathrm{t} 4$; DBP at $\mathrm{t} 0, \mathrm{t} 1, \mathrm{t} 2$, $\mathrm{t} 3$ and $\mathrm{t} 4$; SBP difference between times 0 and 1 ( $\mathrm{t} 0-\mathrm{t} 1)$ and between times 1 and 4 ( $\mathrm{t} 4-\mathrm{t} 1$ ); DBP difference between times 0 and 1 (t0-t1) and between times 1 and 4 (t4-t1).

As additional measures, HR at $\mathrm{t} 0, \mathrm{t} 1, \mathrm{t} 2$ and $\mathrm{t} 4$; HAM-D score at $\mathrm{t} 1, \mathrm{t} 2$, $\mathrm{t} 3$ and $\mathrm{t} 4$; and the change in BMI between $t 1$ and $t 4$ were compared between the two groups were using a Student's $t$ test. A p-value equal to or less than 0.05 was considered significant.

\section{Results}

The present study evaluated 87 patients, 47 (54.02\%) of whom presented with some psycho-emotional disorder, as assessed by the SRQ-20 scale. Seventeen patients were excluded from the final sample; therefore, the study included 30 individuals. Grounds for exclusion were: dropout, participation in another clinical trial, and/or unsuitability due to exclusion and inclusion criteria (mainly oscillating BP levels and diagnosis of substance abuse in the SCID).

According to Table 1, the mean age of the study population was 57.2 years, with a predominance of women (23 versus $7 \mathrm{men}$ ), correlating with the prevalence of depression in the general population (3:1). Fifty percent of the women were homemakers and the rest were employed. Most participants were married $(60 \%)$ and had, on average, 1.38 other chronic diseases. The most frequent comorbid disease was hypercholesterolemia, which affected $40 \%$ of the sample, followed by type- 2 diabetes mellitus (20\%), and hypothyroidism (13\%). On an average, all participants were being treated with 2.3 antihypertensives. There was a prevalence of sedentarism $(80 \%)$ and obesity, with an average BMI of 30.8. Moreover, participants had high scores on the HAM-D scale (26.3), indicating severe depression.

\subsection{Escitalopram versus Placebo Effect}

Table 2, Graph 1, Graph 2 and Graph 3 show the data of escitalopram and placebo groups with their statistical significance.

The initial data revealed no significant difference in terms of age, gender ratio, number of antihypertensive drugs, BMI, SBP, DBP, HAM-D, or sleep score.

The HR, in time 4 ( 2 months), was lower in the escitalopram group than in the placebo group: escitalopram $66.88 \pm 9.62,74.19 \pm 9.55$ vs. placebo bpm, $\mathrm{p}=0.04$ (Graph 3).

In addition, no differences were noted between the final HAM-D score and sleep between placebo and escitalopram groups.

Of the 15 individuals who used escitalopram, 10 had remitting depression and 5 did not. There was a higher proportion of remission in the escitalopram group than in the placebo (58\% vs. 42\%) (Figure 2 and Table 2); however, this finding was not significant (Pearson chi square $=1.222, \mathrm{p}=0.269$ ). A total of 14 individuals regula- 


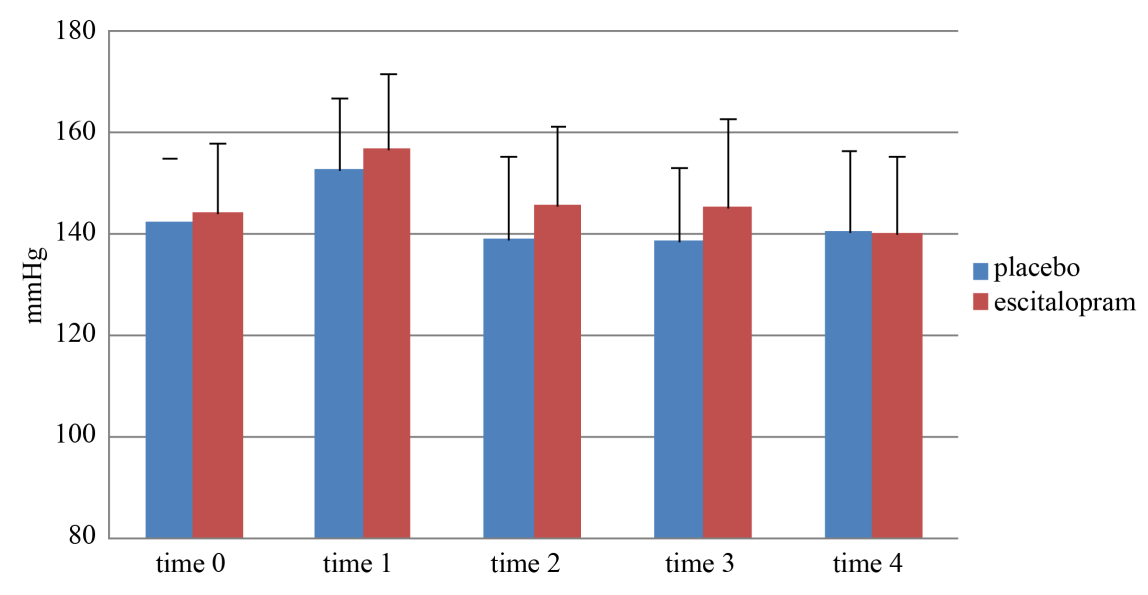

Graph 1. Change in average SBP of the placebo and escitalopram groups.

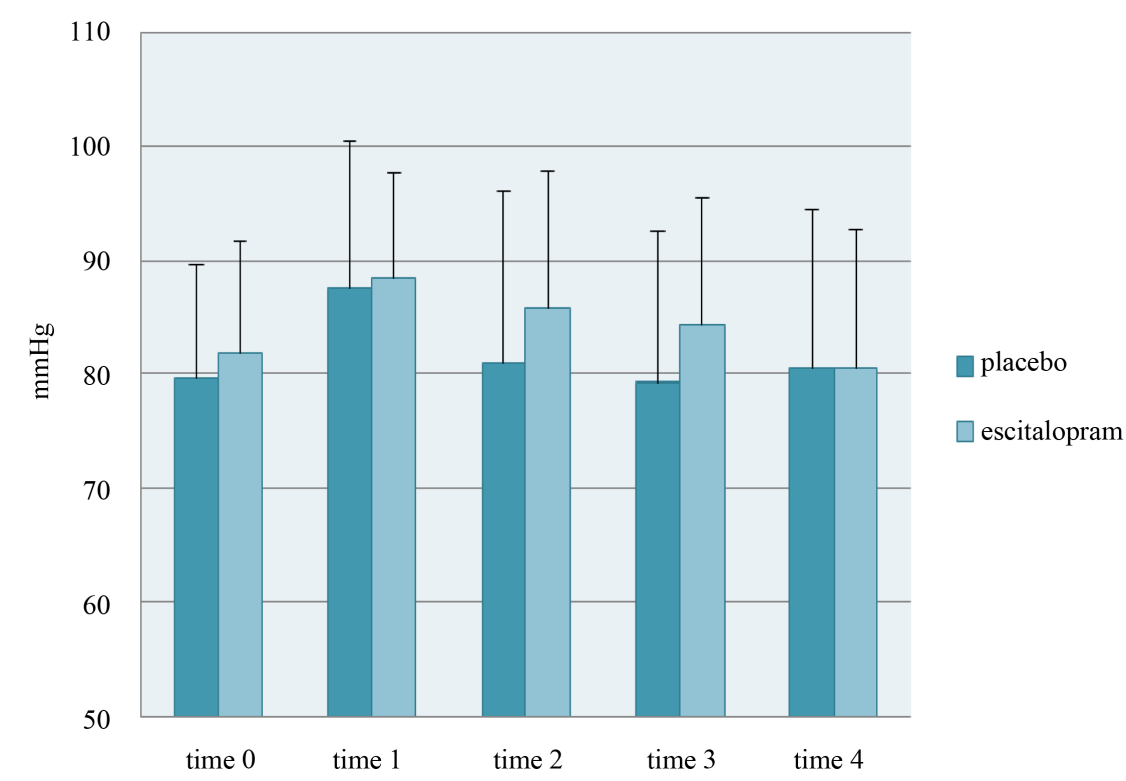

Graph 2. Average variation of DBP of placebo and escitalopram groups.

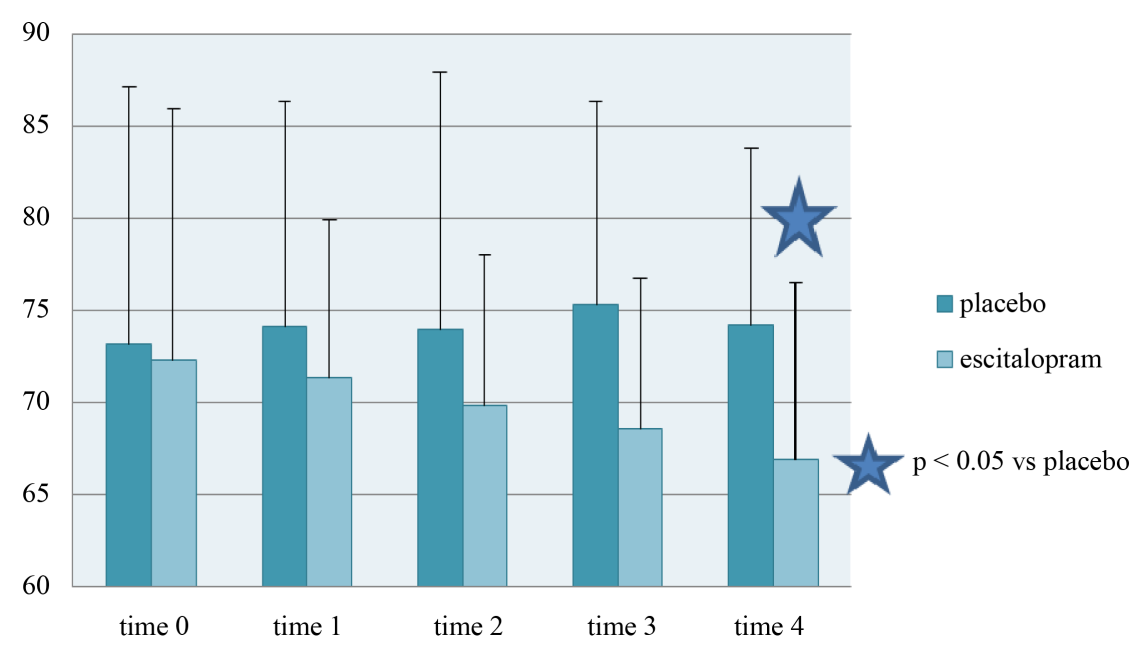

Graph 3. HR average variation in placebo and escitalopram groups. 

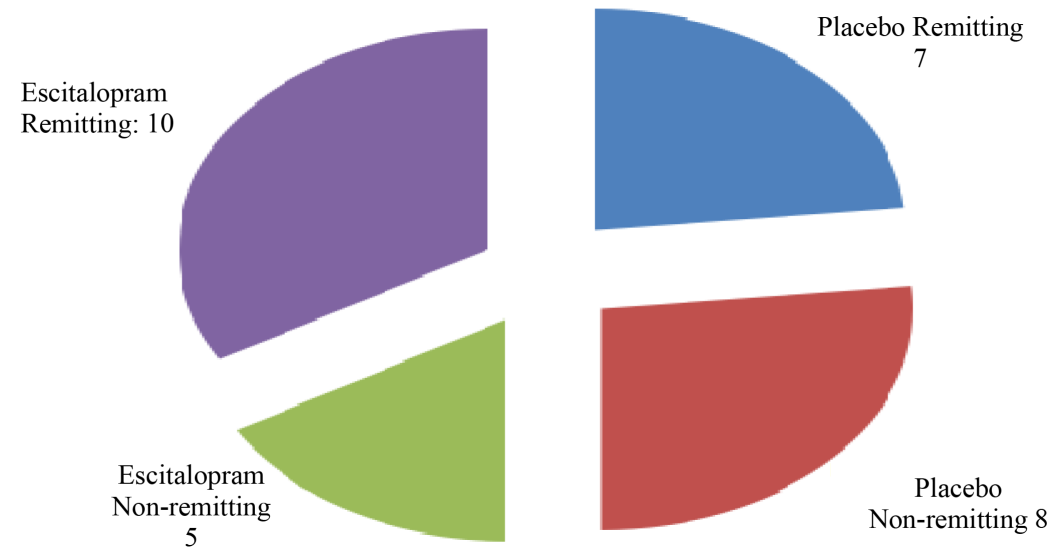

Figure 2. Separation of groups concerning the remission of the depression.

Table 1. General characteristics, anthropometric, social and clinical participants $(n=30)$.

\begin{tabular}{cc} 
Age (years) & $57.2 \pm 6.65$ \\
Gender (male:female) & $7: 23$ \\
Years of education & $6.8 \pm 3.82$ \\
Employment (proportion of housewives) & $50 \%$ \\
Marital status (married) & $60 \%$ \\
Number of chronic diseases & $1.38 \pm 0.52$ DM2 20\% Hypercholesterolemia 40\% Hypothyroidism 13\% \\
Antihypertensive medicine amount at the beginning & $2.3 \pm 0.87$ \\
Smoking & 0 \\
Oral contraceptive & 0 \\
Sedentary lifestyle & $80 \%$ \\
Alcohol & 0 \\
BMI beginning $\left(\mathbf{k g} / \mathbf{m}^{2}\right)$ & $30.8 \pm 6.56$ \\
SBP time 0 (mmHg) & $143.1 \pm 12.81$ \\
DBP time 0 (mmHg) & $80.7 \pm 9.67$ \\
HR time 0 (bpm) & $72.7 \pm 13.57$ \\
HAM-D time 1 & $26.3 \pm 5.50$ \\
Sleep score time 1 & $3.8 \pm 2.06$ \\
\hline
\end{tabular}

rized their sleep (sleep final score equal to zero); of these, 8 (57\%) were in the escitalopram and $6(43 \%)$ in the placebo group (Table 2).

\subsection{Effect of Depression Remission}

Among all the 30 subjects, there was remission of depression in 17 individuals, with $10(58 \%)$ subjects from the escitalopram group and 7 (42\%) from the placebo group (Figure 2). The other group of 13 individuals had non-remitting depression. These groups were formed regardless of medication used. Thus, we were able to investigate whether the remission of depression influenced HR and BP (Table 3, Graph 4 and Graph 5).

DBP (Graph 5) at time 2 was higher in the remitting group $(88.7 \pm 13.63 \mathrm{mmHg})$ than in the non-remitting group $(76.3 \pm 10.08 \mathrm{mmHg}), \mathrm{p}=0.011$.

In the sample of 30 patients, 14 were able to regularize their sleep independent of escitalopram or placebo treatment. Of these 14 subjects with normal sleep, 12 (86\%) showed remission of depression and only two (14\%) 
Table 2. General, anthropometric, social, and clinical characteristics separated according to the participants use of medication $(\mathrm{n}=30)$.

\begin{tabular}{|c|c|c|c|}
\hline & Escitalopram & Placebo & $\mathrm{p}$ \\
\hline Number & 15 & 15 & \\
\hline Age & $56.7 \pm 6.14$ & $57.6 \pm 7.30$ & 0.71 \\
\hline Gender (M:F) & 03:12 & 04:11 & \\
\hline Antihypertensive medicine dose at the study onset & $2.1 \pm 0.99$ & $2.4 \pm 0.74$ & 0.31 \\
\hline Years of education & $7.2 \pm 3.53$ & $6.4 \pm 3.85$ & 0.55 \\
\hline Employment (proportion of housewives) & $53 \%$ & $46 \%$ & \\
\hline Marital status (married) & $66 \%$ & $53 \%$ & \\
\hline Number of chronic diseases & $1.3 \pm 0.51$ & $1.4 \pm 0.51$ & 0,92 \\
\hline Smoking & 0 & 0 & \\
\hline Oral contraceptive & 0 & 0 & \\
\hline Sedentary lifestyle & $93 \%$ & $66 \%$ & \\
\hline Alcohol & 0 & 0 & \\
\hline Initial BMI (kg/m²) & $31.7 \pm 5.85$ & $29.9 \pm 7.29$ & 0.47 \\
\hline Initial BMI $\left(\mathrm{kg} / \mathrm{m}^{2}\right)$ & $31.8 \pm 5.79$ & $29.9 \pm 7.20$ & 0.44 \\
\hline SBP time 0 & $144.0 \pm 13.50$ & $142.2 \pm 12.47$ & 0.70 \\
\hline SBP time 1 & $156.7 \pm 14.64$ & $152.4 \pm 14.23$ & 0.42 \\
\hline SBP time 2 & $145.6 \pm 15.39$ & $138.9 \pm 16.28$ & 0.25 \\
\hline SBP time 3 & $145.1 \pm 17.62$ & $138.5 \pm 14.37$ & 0.27 \\
\hline SBP time 4 & $140.1 \pm 15.12$ & $140.2 \pm 15.83$ & 0.97 \\
\hline DBP time 0 & $81.8 \pm 9.67$ & $79.6 \pm 9.89$ & 0.54 \\
\hline DBP time 1 & $88.4 \pm 9.28$ & $87.4 \pm 13.05$ & 0.8 \\
\hline DBP time 2 & $85.8 \pm 11.91$ & $80.9 \pm 15.02$ & 0.32 \\
\hline DBP time 3 & $84.2 \pm 11.15$ & $79.2 \pm 13.31$ & 0.27 \\
\hline DBP time 4 & $80.5 \pm 12.06$ & $80.4 \pm 14.07$ & 0.98 \\
\hline HR time 0 & $72.3 \pm 13.62$ & $73.1 \pm 13.99$ & 0.871 \\
\hline HR time 1 & $71.3 \pm 8.62$ & $74.1 \pm 12.20$ & 0.473 \\
\hline HR time 2 & $69.8 \pm 8.12$ & $73.9 \pm 13.99$ & 0.336 \\
\hline HR time 3 & $68.5 \pm 8.16$ & $75.2 \pm 11.01$ & 0.067 \\
\hline HR time 4 & $66.8 \pm 9.62$ & $74.1 \pm 9.55$ & $0.0460^{*}$ \\
\hline HAM-D time 1 & $27.9 \pm 4.86$ & $24.7 \pm 5.79$ & 0.11 \\
\hline HAM-D time 4 & $8.2 \pm 7.06$ & $8.2 \pm 3.48$ & 1.00 \\
\hline Sleep score time 1 & $4.4 \pm 1.84$ & $3.2 \pm 2.15$ & 0.11 \\
\hline Sleep score time 4 & $1.8 \pm 2.53$ & $0.8 \pm 0.91$ & 0.16 \\
\hline$\Delta$ time 1 - time 0 SBP & $12.7 \pm 17.88$ & $10.2 \pm 8.34$ & 0.63 \\
\hline$\Delta$ time 0 - 1 time DBP & $6.5 \pm 9.27$ & $7.7 \pm 10.48$ & 0.74 \\
\hline$\Delta$ time 4 - 1 time SBP & $-16.6 \pm 16.15$ & $-12.1 \pm 13.91$ & 0.42 \\
\hline$\Delta$ time 0 - 1 time DBP & $-7.9 \pm 9.29$ & $-6.9 \pm 7.70$ & 0.77 \\
\hline Remitting & $10(58 \%)$ & $7(42 \%)$ & Total 17 \\
\hline Non-remitting & $5(38 \%)$ & $8(61 \%)$ & Total 13 \\
\hline Normal sleep & $8(57 \%)$ & $6(43 \%)$ & Total 14 \\
\hline Sleepless & $7(43 \%)$ & $9(56 \%)$ & Total 16 \\
\hline
\end{tabular}


Table 3. General, anthropometric, social, and clinical characteristics separated according to the remission status of participants $(n=30)$.

\begin{tabular}{|c|c|c|c|}
\hline & Remitting & Non-remitting & $\mathbf{p}$ \\
\hline Number & 17 & 13 & \\
\hline Age & $56.2 \pm 5.92$ & $59 \pm 8.43$ & 0.31 \\
\hline Gender & $04: 13$ & $03: 10$ & \\
\hline Antihypertensive medicine dose at the study onset & $2.2 \pm 1.03$ & $2.3 \pm 0.65$ & 0.65 \\
\hline Years of education & $6.7 \pm 3.11$ & $7 \pm 4.39$ & 0.86 \\
\hline Employment (proportion of housewives) & $41 \%$ & $53 \%$ & \\
\hline Marital status (married) & $52 \%$ & $61 \%$ & \\
\hline Number of chronic diseases & $1.4 \pm 0.52$ & $1.2 \pm 0.46$ & 0.39 \\
\hline Smoking & 0 & 0 & \\
\hline Oral contraceptive & 0 & 0 & \\
\hline Sedentary lifestyle & $71 \%$ & $93 \%$ & \\
\hline Alcohol & 0 & 0 & \\
\hline Initial BMI (kg/m²) & $29.4 \pm 5.99$ & $32.6 \pm 7.06$ & 0.19 \\
\hline Initial BMI (kg/m²) & $29.4 \pm 5.76$ & $32.8 \pm 7.10$ & 0.16 \\
\hline SBP time 0 & $142.6 \pm 12.65$ & $143.7 \pm 13.49$ & 0.82 \\
\hline SBP time 1 & $157.1 \pm 15.83$ & $151.2 \pm 11.94$ & 0.27 \\
\hline SBP time 2 & $146.6 \pm 16.39$ & $136.5 \pm 13.84$ & 0.08 \\
\hline SBP time 3 & $144.0 \pm 17.89$ & $138.8 \pm 13.66$ & 0.39 \\
\hline SBP time 4 & $141.2 \pm 16.33$ & $138.8 \pm 14.15$ & 0.68 \\
\hline DBP time 0 & $81.3 \pm 10.47$ & $79.9 \pm 8.87$ & 0.69 \\
\hline DBP time 1 & $90.9 \pm 11.37$ & $84.0 \pm 9.90$ & 0.09 \\
\hline DBP time 2 & $88.7 \pm 13.63$ & $76.3 \pm 10.08$ & $0.01^{*}$ \\
\hline DBP time 3 & $84.4 \pm 12.54$ & $78.1 \pm 11.56$ & 0.17 \\
\hline DBP time 4 & $84.2 \pm 14.05$ & $75.6 \pm 9.62$ & 0.07 \\
\hline HR Time 0 & $73.6 \pm 13.65$ & $71.5 \pm 13.94$ & 0.68 \\
\hline HR Time 1 & $72.2 \pm 9.69$ & $73.3 \pm 11.81$ & 0.79 \\
\hline HR Time 2 & $72.0 \pm 10.63$ & $71.7 \pm 12.85$ & 0.94 \\
\hline HR Time 3 & $70.6 \pm 9.30$ & $73.5 \pm 11.30$ & 0.46 \\
\hline HR Time 4 & $70.4 \pm 9.93$ & $70.6 \pm 10.80$ & 0.95 \\
\hline HAM-D time 1 & $26.9 \pm 5.03$ & $25.5 \pm 6.18$ & 0.50 \\
\hline HAM-D time 4 & $4.6 \pm 3.06$ & $12.8 \pm 4.31$ & $0^{*}$ \\
\hline Sleep score time 1 & $3.4 \pm 2.00$ & $4.3 \pm 2.10$ & 0.24 \\
\hline Sleep score time 4 & $0.8 \pm 1.81$ & $2.0 \pm 1.93$ & 0.08 \\
\hline$\Delta$ time $4-1$ time SBP & $14.4 \pm 14.76$ & $7.4 \pm 11.72$ & 0.17 \\
\hline$\Delta$ time 0 - 1 time DBP & $9.5 \pm 8.40$ & $4.0 \pm 10.80$ & 0.12 \\
\hline$\Delta$ time 1 - time 0 SBP & $-15.9 \pm 15.88$ & $-12.4 \pm 14.10$ & 0.53 \\
\hline$\Delta$ time 1 - time 4 PAD & $-6.7 \pm 8.76$ & $-8.3 \pm 8.14$ & 0.61 \\
\hline Normal sleep & $12(86 \%)$ & $2(14 \%)$ & Total 14 \\
\hline Sleepless & $5(31 \%)$ & $11(69 \%)$ & Total 16 \\
\hline Escitalopram & $10(67 \%)$ & $5(33 \%)$ & Total 15 \\
\hline Placebo & $7(47 \%)$ & $8(53 \%)$ & Total 15 \\
\hline
\end{tabular}




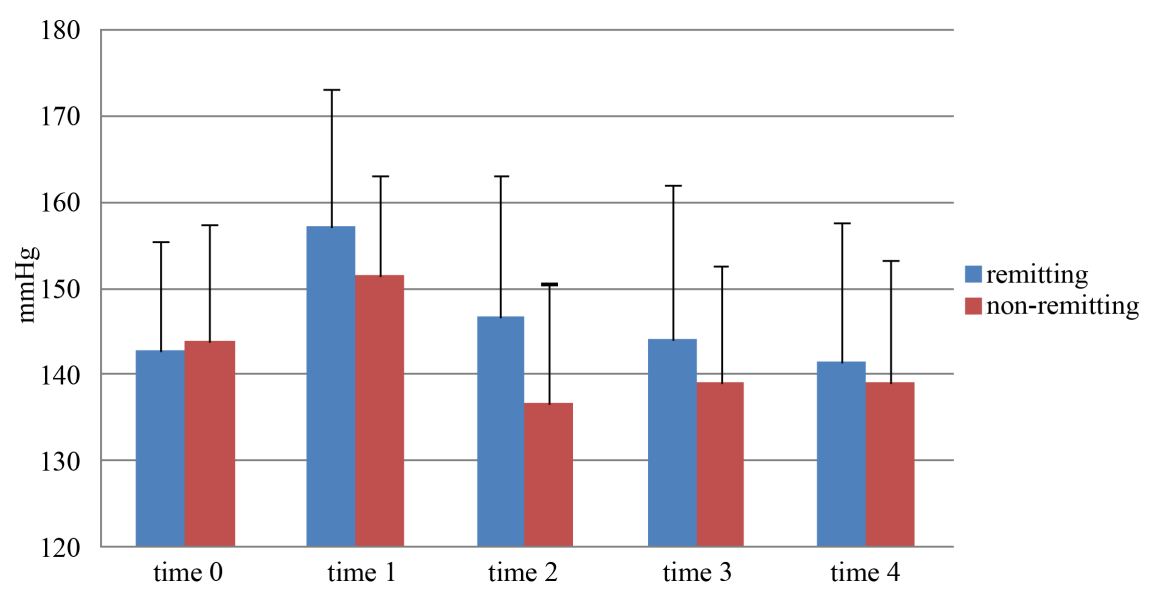

Graph 4. Changes in average SBP of remitting and non-remitting groups.

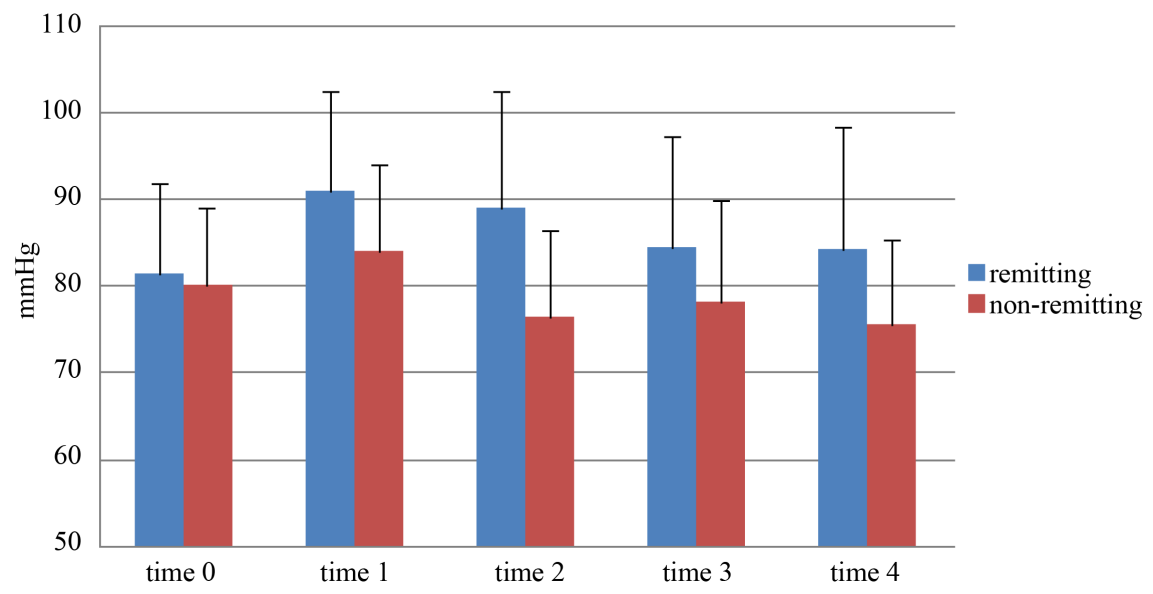

Graph 5. Changes in average DBP of remitting and non-remitting groups.

showed no improvement (Table 3).

\subsection{Sleep Regularization Effect}

After obtaining sleep scores (Table 4), patients were divided into a normal sleep group $(n=14)$ with a final sleep score of 0 , and a sleepless group $(n=16)$ with sleep scores $\geq 1$.

Since the study onset, there was no difference in terms of age, number of antihypertensive drugs taken, BMI, HR, HAM-D, and sleep across all participants. Interestingly, a higher proportion of men were fallen into the normal sleep group $(55 \% \times 14 \%)$ than woman.

With regard to the SBP, according to Table 3 and Graph 6, there was a significant decrease in the average SBP of the normal sleep group during treatment. This was not observed in the insomniac group ( $\Delta \mathrm{t} 1-\mathrm{t} 4:-20.07$ $\pm 13.45 \times-9.43 \pm 14.87 \mathrm{mmHg} ; \mathrm{p}=0.04)$.

For the DBP (Graph 7), it was observed that the normal sleep group had a significant increase during the wash-out period $(\Delta \mathrm{t} 0$-t1: $11.4 \pm 8.04 \times 3.4 \pm 9.79 \mathrm{mmHg} ; \mathrm{p}=0.02)$.

At time 4 , the normal sleep group had average scores on the HAM-D scale that were significantly lower: $4.5 \pm$ $3.52 \times 11.4 \pm 4.81, \mathrm{p} \leq 0.001$.

In the sample as a whole $(\mathrm{n}=30)$, there were 17 individuals with remitting depression, and $12(71 \%$ of the 17 remitting) belonged to the normal sleep group while 5 (29\%) belonged to the insomniac group (Figure 3 and Table 4). In the non-remitted depression group (13 persons), only 2 participants (15\% of non-remitting 13 ) had normal sleep, while $11(85 \%)$ remained insomniacs (Table 4). This difference was statistically significant (chi square $=9.020$ Pearson, $\mathrm{p}=0.003$ ). 
Table 4. General, anthropometric, social, and clinical characteristics separated according to sleep status $(n=30)$.

\begin{tabular}{|c|c|c|c|}
\hline & Normal sleep & Sleepless & $\mathrm{p}$ \\
\hline Number & 14 & 16 & \\
\hline Age & $55.0 \pm 6.98$ & $59.5 \pm 6.75$ & 0.084 \\
\hline Gender & 05:09 (55\%) & $02: 14(14 \%)$ & \\
\hline Antihypertensive medicine amount at the beginning & $2.3 \pm 1.08$ & $2.2 \pm 0.68$ & 0.74 \\
\hline Years of education & $7.2 \pm 3.98$ & $6.5 \pm 3.42$ & 0.56 \\
\hline Employment (proportion of housewives) & $42 \%$ & $50 \%$ & \\
\hline Marital status (married) & $64 \%$ & $43 \%$ & \\
\hline Number of chronic diseases & $1.5 \pm 0.53$ & $1.3 \pm 0.48$ & 0.41 \\
\hline Smoking & 0 & 0 & \\
\hline Oral contraceptive & 0 & 0 & \\
\hline Sedentary lifestyle & $71 \%$ & $87 \%$ & \\
\hline Alcohol & 0 & 0 & \\
\hline Initial BMI $\left(\mathrm{kg} / \mathrm{m}^{2}\right)$ & $29.8 \pm 6.35$ & $31.7 \pm 6.81$ & 0.44 \\
\hline Initial BMI $\left(\mathrm{kg} / \mathrm{m}^{2}\right)$ & $29.6 \pm 6.13$ & $32.0 \pm 6.78$ & 0.32 \\
\hline SBP time 0 & $139.0 \pm 13.39$ & $146.7 \pm 11.49$ & 0.1 \\
\hline SBP time 1 & $155.4 \pm 16.74$ & $153.8 \pm 12.44$ & 0.77 \\
\hline SBP time 2 & $142.0 \pm 16.83$ & $142.4 \pm 15.65$ & 0.94 \\
\hline SBP time 3 & $138.1 \pm 17.27$ & $145.0 \pm 14.90$ & 0.25 \\
\hline SBP time 4 & $135.3 \pm 16.40$ & $144.4 \pm 13.15$ & 0.1 \\
\hline DBP time 0 & $79.1 \pm 9.66$ & $82.1 \pm 9.79$ & 0.41 \\
\hline DBP time 1 & $90.6 \pm 12.88$ & $85.6 \pm 9.15$ & 0.22 \\
\hline DBP time 2 & $86.8 \pm 13.02$ & $80.4 \pm 13.71$ & 0.2 \\
\hline DBP time 3 & $81.3 \pm 11.69$ & $82.0 \pm 13.24$ & 0.88 \\
\hline DBP time 4 & $80.3 \pm 12.80$ & $80.6 \pm 13.37$ & 0.96 \\
\hline HR Time 0 & $72.5 \pm 15.02$ & $72.9 \pm 12.66$ & 0.93 \\
\hline HR Time 1 & $73.5 \pm 9.75$ & $71.9 \pm 11.34$ & 0.68 \\
\hline HR Time 2 & $74.3 \pm 10.35$ & $69.7 \pm 12.23$ & 0.28 \\
\hline HR Time 3 & $73.9 \pm 9.26$ & $70.1 \pm 10.82$ & 0.32 \\
\hline HR Time 4 & $71.9 \pm 10.17$ & $69.2 \pm 10.25$ & 0.47 \\
\hline HAM-D time 1 & $25.1 \pm 4.97$ & $27.3 \pm 5.88$ & 0.27 \\
\hline HAM-D time 4 & $4.5 \pm 3.52$ & $11.4 \pm 4.81$ & 0.00012 \\
\hline Sleep score time 1 & $3.5 \pm 2.17$ & $4.1 \pm 1.99$ & 0.47 \\
\hline Sleep score time 4 & 0 & $2.5 \pm 1.99$ & 0 \\
\hline$\Delta$ time $4-1$ time SBP & $16.3 \pm 14.54$ & $7.1 \pm 11.85$ & 0.065 \\
\hline$\Delta$ time 0 - 1 time DBP & $11.4 \pm 8.04$ & $3.4 \pm 9.79$ & 0.02 \\
\hline$\Delta$ time 1 - time 0 SBP & $-20.0 \pm 13.45$ & $-9.4 \pm 14.87$ & 0.049 \\
\hline$\Delta$ time 1 - time 4 PAD & $-10.2 \pm 6.27$ & $-5.0 \pm 9.41$ & 0.089 \\
\hline Remitting & $12(71 \%)$ & $5(29 \%)$ & Total 17 \\
\hline Non-remitting & $2(15 \%)$ & $11(85 \%)$ & Total 13 \\
\hline Escitalopram & $8(54 \%)$ & $7(46 \%)$ & Total 15 \\
\hline Placebo & $6(40 \%)$ & $9(60 \%)$ & Total 15 \\
\hline
\end{tabular}




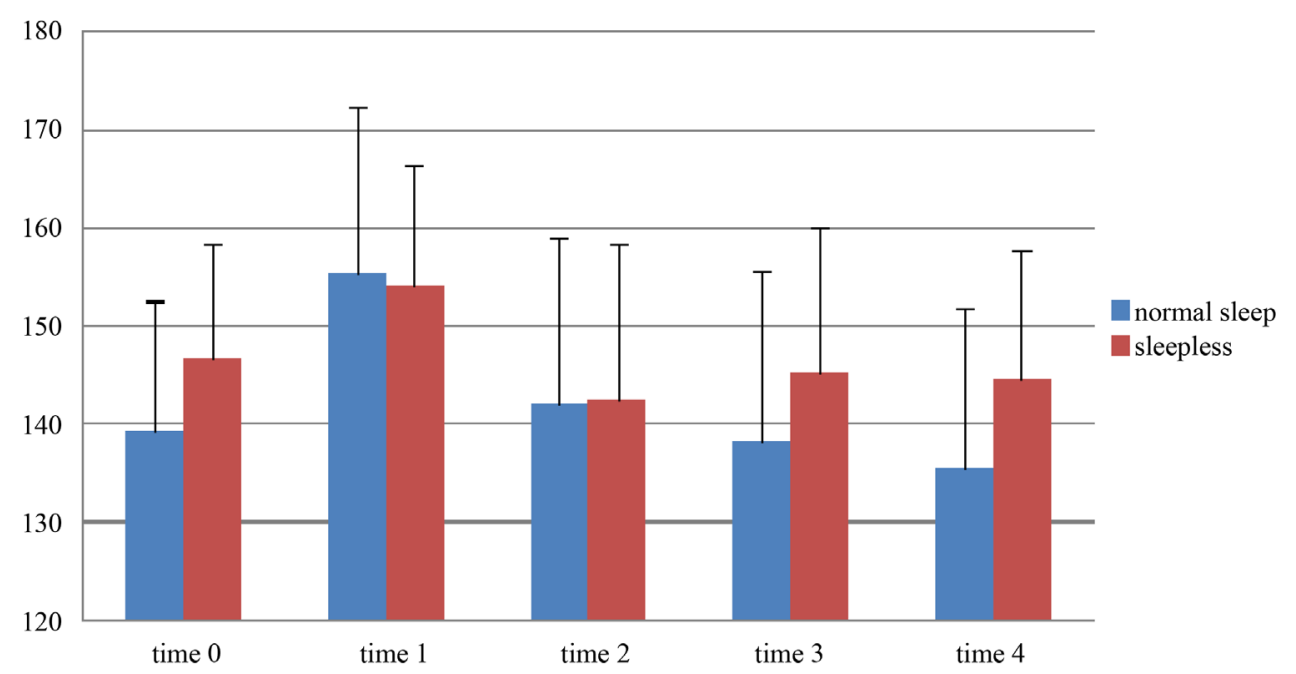

Graph 6. Change in average SBP normal sleep and sleepless groups.

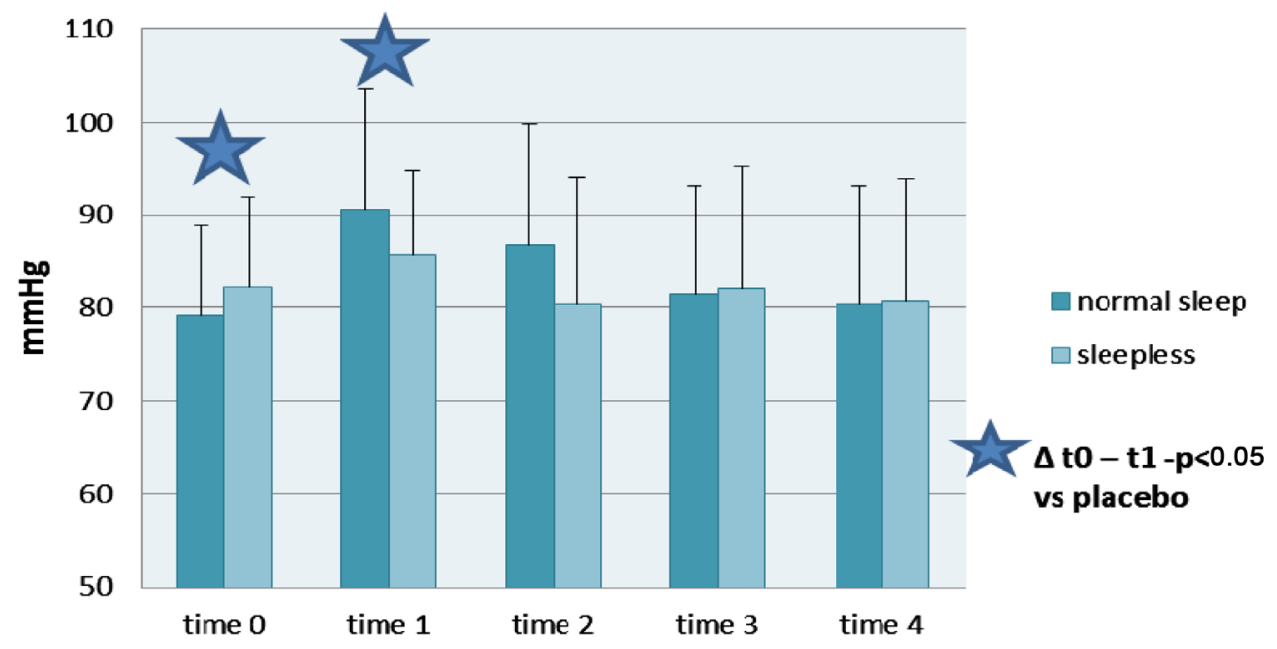

Graph 7. Change in average DBP normal sleep and sleepless groups.

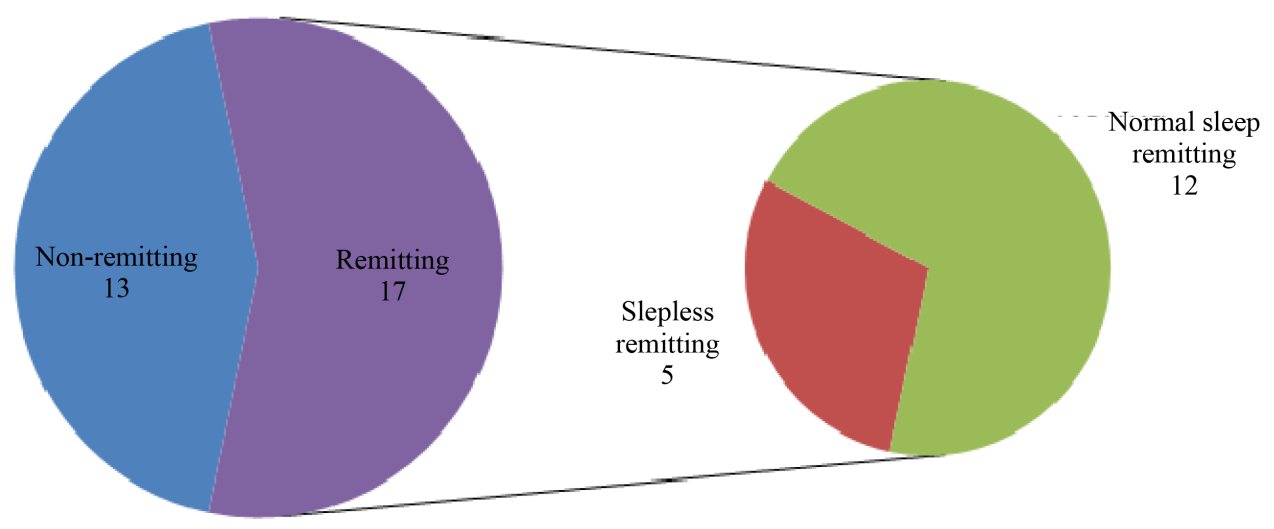

Figure 3. Separation of the groups based on sleep quality.

Finally, of the 15 individuals who used escitalopram, 8 (54\%) achieved regularized sleep while 7 (46\%) remained sleepless. 


\section{Discussion}

This was the first prospective clinical, placebo-controlled, randomized, and double-blind study to follow the evolution of hemodynamic parameters (BP and HR) in subjects with hypertension and depression that were being treated with escitalopram, an antidepressant of the selective serotonin reuptake inhibitors class.

Hypertension is largely prevalent ( $40 \%$ of the global population [35]), just like depression ( 350 million people worldwide [36]). Both diseases also have great social impacts, as they are the two leading causes of disability worldwide [37]. Nevertheless, few controlled clinical studies have investigated interactions between these two diseases. Currently, most evidence of this interaction comes from epidemiological studies [11]-[14] that have compared the prevalence and/or incidence of depression and hypertension in different contexts; however, according to Sibald [38], "controlled clinical trials are the most rigorous way to determine if there is a cause and effect relationship between a treatment and its outcome".

Other clinical studies have addressed the situation differently. Swarts and Inglis [39], for example, analyzed 48 patients hospitalized for depression, and found a reduction of at least $20 \mathrm{mmHg}$ SBP in 15 patients who had improved depression symptoms due to electroconvulsive therapy.

Therefore, this is the first clinical study to indicate that the selective serotonin reuptake inhibitor, escitalopram, can reduce the HR of individuals with hypertension and depression. Thus, it can be inferred that the decrease in HR is independent of depression remission. This is clearly shown in Table 3 where, after separating out group variables, the decrease in HR for individuals in the placebo group at $t 4$ is not statistically significant $(70.44 \pm$ 9.93 to remitting and $70.66 \pm 10.80 \mathrm{bpm}$ to non-remitting, $\mathrm{p}=0.95$ ), but is significant for those who take escitalopram (Graph 3). The decrease in HR was also independent of sleep regularization, as shown in Table 4. It can also be observed that HR at 44 does not show any statistically significant change $(71.99 \pm 10.17 \mathrm{bpm})$ in sleep or group $(69.26 \pm 0.25 \mathrm{bpm})$ in the sleepless group $(\mathrm{p}=0.47)$.

Malik et al. [40] argued that HR was an important marker of the activity of the sympathetic nervous system. Thus, the decrease in HR by escitalopram in this study supports the theory that the sympathetic nervous system is an important mediator between hypertension and depression. Perhaps using other physiological measures, such as plasma dosage of norepinephrine, would increase the number of observations made on the interaction of these two diseases.

When comparing placebo and escitaloprom groups, only HR (but not BP) is statistically different. This may be because HR is more sensitive to physiological changes of the autonomic nervous system than BP [39]. In longer and larger sample studies, perhaps the difference in escitalopram and placebo groups will also affect BP.

Regarding the remission of depression, this study did not show significant changes in BP or HR (Table 3, Graph 4 and Graph 5). In this study, the rate of depression remission with placebo was high (41\% of patients remitted with the placebo, while $51 \%$ remitted with escitalopram (Figure 2)), generating a lack of statistical difference (chi-square test $=1.222, \mathrm{p}=0.269$ ). From these data, the efficacy of escitalopram could be contested, or the placebo could be suggested to be extraordinarily efficient. However, the Einarson review study [41] on a total of 997 individuals showed similar percentage averages as our results $(37.6 \%$ remission with placebo and $48.7 \%$ remission with escitalopram). Their larger study population yielded a statistically significant difference among groups $(\mathrm{p}=0.003)$.

This is also the first clinical, placebo-controlled, randomized, and double-blinded study to show a significant drop in SBP (Table 4 and Graph 6) during the course of treatment in terms of sleep regularization.

According to Figure 3 and Table 4, we concluded that greater sleep regularization occurred with depression remission ( $71 \%$ of the 17 individuals remitting) when compared with individuals who remained depressed (only $15 \%$ had regular sleep of the 13 non-remitting individuals) (chi-square $=9.020$ Pearson, $p=0.003$ ). According to Buysse et al. [42], depression is the most important cause of insomnia. Moreover, Carney et al. [43] found a reduction of insomnia in $79 \%$ of patients who were in depression remission due to antidepressants.

This observation reinforces the conclusion of Gangwisch et al. [44] in which insomnia can be the mediating factor between hypertension and depression. This study conducted a longitudinal multivariate analysis (19821992) using the First National Health and Nutrition Examination Survey $(n=4913)$ database and observed that individuals suffering from depression were $44 \%$ more likely to develop hypertension. Including insomnia and sleep duration of less than 6 hours in a multivariate analysis revealed that there was a considerable decrease $(27 \%)$ in the chance of these depressed individuals developing hypertension.

The gold standard of treatment for obstructive sleep apnea, another sleep disorder, through continuous posi- 
tive airway pressure, has also been shown to decrease BP in subjects with resistant hypertension. As indexes of obstructive sleep apnea improved, SBP fell to $7 \mathrm{mmHg}$ and DBP dropped to $5 \mathrm{mmHg}$. Moreover, in the control group who was not getting treated for obstructive sleep apnea, they observed an increase of SBP and DBP to 3 $\mathrm{mmHg}$ and $2 \mathrm{mmHg}$, respectively [45].

Other evidence suggests that sleep deprivation leads to an increase in BP. In one study, it is noted that sleep deprived university students have reduced endothelial vasodilation during their final examinations, which may lead to increased BP [46]. Individuals with fatal familial insomnia, which causes total sleep deprivation, also exhibit dysautonomia, adrenal hyperactivity, and hypertension [47]. Other studies have shown the influence of sleep on the development of both SH [48] and depression [49].

It is noteworthy that the sleep parameter is more perceived by the patient than other measures of depression (e.g., volition, self-esteem, and cognition), and is therefore easier to measure. Moreover, patients can more easily identify an improvement in sleep than in self-esteem. Perhaps because of this, the difference observed in this study appeared in the sleep parameter rather than in the improvement of depression.

Our study also has the following limitations: the total sample of 30 subjects ( 15 per group) can be considered small; the semiautomatic digital sphygmomanometer used to measure BP and HR can generate observation bias (being more indicated the use of 24 hours ambulatory blood pressure monitoring device) [50]; and finally the observation time of two months may be considered short. This latter limitation seems evident, because by observing chart 4, the intervention group displays a downward trend in SBP values over time and this trend can continue if the intervention time is prolonged.

The results of this study are consistent with the hypothesis that antidepressant treatment, with or without medication, has influence on SH and HR. The methodology can be used and improved for further studies to investigate the relationship between the two diseases, an interaction which lacks appropriate clinical studies.

As a final observation, this work leaves a message to clinicians that currently treat hypertension that they should be more attentive to comorbid depression. Moreover, it is essential that they intervene in these cases for better control of blood pressure. Likewise, doctors treating depression should also assess for SH. In conclusion, this study advocates a comprehensive care of the patient—one that does not separate between physical and emotional illnesses.

\section{Conflicts of Interest and Source of Funding}

Escitalopram was provided by Lundbeck. Torrent provided the losartan and hydrochlorothiazide.

\section{References}

[1] Wells, K.B. (1996) Caring for Depression. Harvard University Press, Cambridge.

[2] Lett, H.S., Blumenthal, J.A. and Babyak, M.A. (2004) Depression as a Risk Factor for Coronary Artery Disease: Evidence, Mechanisms, and Treatment. Psychosomatic Medicine, 66, 305-315.

[3] Stewart, R.A., North, F.M. and West, T.M. (2003) Depression and Cardiovascular Morbidity and Mortality: Cause or Consequence? European Heart Journal, 24, 2027-2037. http://dx.doi.org/10.1016/j.ehj.2003.08.017

[4] Evans, D.L., Charney, D.S. and Lewis, L. (2005) Mood Disorders in the Medically Ill: Scientific Review and Recommendations. Biological Psychiatry, 58, 175-189. http://dx.doi.org/10.1016/j.biopsych.2005.05.001

[5] Borowicz Jr., L., Royall, R., Greek, M., Selnes, O., Lyketsos, C. and McKhann, G. (2002) Depression and Cardiac Morbidity 5 Years after Coronary Artery Bypass Surgery. Psychosomatics, 43, 464-471. http://dx.doi.org/10.1176/appi.psy.43.6.464

[6] Egede, L.E. (2007) Major Depression in Individuals with Chronic Medical Disorders: Prevalence, Correlates and Association with Health Resource Utilization, Lost Productivity and Functional Disability. General Hospital Psychiatry, 29, 409-416. http://dx.doi.org/10.1016/j.genhosppsych.2007.06.002

[7] Adamis, D. and Ball, C. (2000) Physical Morbidity in Elderly Psychiatric Inpatients: Prevalence and Possible Relations between the Major Mental Disorders and Physical Illness. International Journal of Geriatric Psychiatry, 15, 248-253. http://dx.doi.org/10.1002/(SICI)1099-1166(200003)15:3<248::AID-GPS102>3.0.CO;2-L

[8] Nakagawara, M., Witzke, W. and Matussek, N. (1987) Hypertension in Depression. Psychiatry Research, 21, 85-86. http://dx.doi.org/10.1016/0165-1781(87)90065-5

[9] Amaral, G.F., Jardim, P.C.B.V., Brasil, M.A.A., Souza, A.L.L., Freitas, H.F., Taniguchi, L.M., Melo, A.F.B. and Ribeiro C.N. (2007) Prevalência de transtorno depressivo maior em centro de referência no tratamento de hipertensão ar- 
terial. Revista de Psiquiatria do Rio Grande do Sul, 29, 161-168.

[10] Bensenor, I.M., Pereira, A.C., Tannuri, A.C., Valeri, C.M., Akashi, D., Fucciolo, D.Q., Issa, F.K., Lobato, M.L., Titan, S.M.O., Galvao, T.G. and Lotufo, P.A. (1998) Hipertensão arterial sistêmica e morbidade psiquiátrica em ambulatório de hospital terciário. Arquivos de Neuropsiquiatria, 56, 406-411.

[11] Jonas, B.S., Franks, P. and Ingram, D.D. (1997) Are Symptoms of Anxiety and Depression Risk Factors for Hypertension? Longitudinal Evidence from the National Health and Nutrition Examination Survey Epidemiologic I Follow-Up Study. Archives of Family Medicine, 6, 43-49. http://dx.doi.org/10.1001/archfami.6.1.43

[12] Rabkin, J., Charles, E. and Kass, F. (1983) Hypertension and DSM-III Depression in Psychiatric Outpatients. American Journal of Psychiatry, 140, 1072-1074. http://dx.doi.org/10.1176/ajp.140.8.1072

[13] Everson, A.S., Kaplan, G.A., Goldberg, D.E. and Salomen, J.T. (2000) Hypertension Incidence Is Predicted by High Levels of Hopelessness in Finnish Men. Hypertension, 34, 561-567. http://dx.doi.org/10.1161/01.HYP.35.2.561

[14] Poulter, N.R., Khaw, K.T., Hopwood, B.E.C., Mugambi, M., Peart, W.S., Rose, G. and Sever, P.S. (1990) The Kenyan Luo Migration Study: Observations on the Initiation of the Rise in Blood Pressure. British Medical Journal, 300, $967-$ 972. http://dx.doi.org/10.1136/bmj.300.6730.967

[15] Brenner, B. and Rector, F. (2011) Brenner and Rector's The Kidney. 9th Edition, Saunders, Philadelphia.

[16] Goodwin, F.K. and Jamison, R.K. (2010) Doença maníaco depressive, transtorno bipolar e depressão recorrente. 2nd Edition, ARTMED, Porto Alegre.

[17] Giacaglia, L.R., Silva, M.E.R. and Santos, R.F. (2010) Tratado de Síndrome Metabólica. Roca, São Paulo.

[18] Deicken, R.F. (1986) Captopril Treatment of Depression. Biological Psychiatry, 21, 1425-1428. http://dx.doi.org/10.1016/0006-3223(86)90334-3

[19] Zubenko, G.S. and Nixon, R.A. (1984) Mood Elevating Effect of Captopril in Depressed Patients. American Journal of Psychiatry, 141, 110-111. http://dx.doi.org/10.1176/ajp.141.1.110

[20] Gard, P.R. (2004) Angioteinsin as a Target for the Treatment of Alzheimer's Disease, Anxiety and Depression. Expert Opinion on Therapeutic Targets, 8, 7-14. http://dx.doi.org/10.1517/14728222.8.1.7

[21] Giardina, W.J. and Ebert, D.M. (1989) Positive Effects of Captopril in the Behavioral Despair Swim Test. Biological Psychiatry, 25, 697-702. http://dx.doi.org/10.1016/0006-3223(89)90240-0

[22] Martin, P., Massol, J. and Puech, A.J. (1990) Captopril as an Antidepressant? Effects on the Learned Helplessness Paradigm in Rats. Biological Psychiatry, 27, 968-974. http://dx.doi.org/10.1016/0006-3223(90)90034-Y

[23] Emanuele, E., Geroldi, D., Minoretti, P., Coen, E. and Politi, P. (2005) Increased Plasma Aldosterone in Patients with Clinical Depression. Archives of Medical Research, 36, 544-548. http://dx.doi.org/10.1016/j.arcmed.2005.03.046

[24] Murck, H., Held, K., Ziegenbein, M., Künzel, H., Koch, K. and Steiger, A. (2003) The Renin-Angiotensin-Aldosterone System in Patients with Depression Compared to Controls-A Sleep Endocrine Study. BMC Psychiatry, 3, 15-23. http://dx.doi.org/10.1186/1471-244X-3-15

[25] Bhattacharyya, N. and Kepnes, L.J. (2012) Ambulatory Office Visits and Medical Comorbidities Associated with Obstructive Sleep Apnea. Otolaryngology_Head and Neck Surgery, 147, 1154-1157. http://dx.doi.org/10.1177/0194599812459850

[26] Blumenthal, J.A., Williams, R.S., Wallace, A.G., Williams Jr., R.B. and Needles, T.L. (1982) Physiological and Psychological Variables Predict Compliance to Prescribed Exercise Therapy in Patients Recovering from Myocardial Infarction. Psychosomatic Medicine, 44, 519-527. http://dx.doi.org/10.1097/00006842-198212000-00003

[27] Kaplan, G.A., Lazarus, N.B., Cohen, R.D. and Leu, D.J. (1991) Psychosocial Factors in the Natural History of Physical Activity. American Journal of Preventive Medicine, 7, 12-17.

[28] Sociedade Brasileira de Cardiologia / Sociedade Brasileira de Hipertensão / Sociedade Brasileira de Nefrologia (2010) VI Diretrizes Brasileiras de Hipertensão. Arquivos Brasileiros de Cardiologia, 95, 1-51.

[29] Mari, J.J. and Williams, P. (1986) A Validity Study of a Psychiatric Screening Questionnaire (SRQ-20) in Primare Care in the City of Sao Paulo. British Journal of Psychiatry, 148, 23-26. http://dx.doi.org/10.1192/bip.148.1.23

[30] National Institute on Alcohol Abuse and Alcoholism (NIAAA)_Alcohol Alert, No. 16, 1992. http://pubs.niaaa.nih.gov/publications/aa16.htm

[31] Palombo, O.J., Hoywaert, E., Bistran, B.R. and Blakburn, G.L. (1981) Nutritional Assessment of the Obese Pacientes. In: Leverson, S.M., Ed., Nutritional Assessment-Present Status, Future Directions and Prospects, Ross Lab, Columbus, 3-10.

[32] Spitzer, R.L., Williams, J.B.W., Gibbon, M. and First, M.B. (1989) Instruction Manual for the Structured Clinical Interview for DSMIIIR (SCID, 5/1/89 Revision). Biometrics Research Department, New York State Psychiatric Institute.

[33] Moreno, R.A. and Moreno, D.H. (1988) Escalas de depressão de Montgomery \& Asberg (MADRS) e de Hamilton 
(HAM-D). Revista de Psiquiatria Clínica, 25, 262-272.

[34] Kendall, J.M. (2003) Designing a Research Project: Randomized Controlled Trials and Their Principles. Emergency Medicine Journal, 20, 164-168. http://dx.doi.org/10.1136/emj.20.2.164

[35] World Health Organization (WHO). Raised Blood Pressure. http://www.who.int/gho/ncd/risk_factors/blood_pressure_prevalence_text/en/

[36] Marcus, M., Yasamy, M.T., Ommeren, M., Chisholm, D. and Saxena, S. (2012) DEPRESSION: A Global Public Health Concern. http://www.who.int/mental_health/management/depression/who_paper_depression_wfmh_2012.pdf

[37] Wells, K.B. (1996) Caring for Depression. Harvard University Press, Cambridge.

[38] Sibbald, B. and Roland, M. (1998) Understanding Controlled Trials: Why Are Randomized Controlled Trials Important? British Medical Journal, 316, 201. http://dx.doi.org/10.1136/bmj.316.7126.201

[39] Swarts, C.M. and Inglis, A.E. (1990) Blood Pressure Reduction with ECT Response. Journal of Clinical Psychiatry, 51, 414-416.

[40] Malik, M. (1996) Heart Rate Variability—Standards of Measurement, Physiological Interpretation, and Clinical Use. Circulation, 93, 1043-1065. http://dx.doi.org/10.1161/01.CIR.93.5.1043

[41] Einarson, T.R. (2004) Evidence Based Review of Escitalopram in Treating Major Depressive Disorder in Primary Care. International Clinical Psychopharmacology, 19, 305-310. http://dx.doi.org/10.1097/01.yic.0000139342.22133.77

[42] Buysse, D.J., Angst, J., Gamma, A., Ajdacic, V., Eich, D. and Rossler, W. (2008) Prevalence, Course and Comorbidity of Insomnia and Depression in Young Adults. Sleep, 31, 473-480.

[43] Carney, E.C., Segal, Z.V., Edinger, J.D. and Krystal, A.D. (2007) A Comparison of Rates of Residual Insomnia Symptoms Following Pharmacotherapy or Cognitive-Behavioral Therapy for Major Depressive Disorder. Journal of Clinical Psychiatry, 68, 254-260. http://dx.doi.org/10.4088/JCP.v68n0211

[44] Gangwisch, J.E., Malaspina, D., Posner, K., Babiss, L.A., Heymsfield, S.B., Turner, J.B., Zammit, G.K. and Pickering, T.G. (2010) Insomnia and Sleep Duration the Mediators of the Relationship between Depression and Hypertension Incidence. American Journal of Hypertension, 23, 62-69. http://dx.doi.org/10.1038/ajh.2009.202

[45] Pedrosa, R.P., Drager, L.F., Paula, L.K., Amaro, A.C., Bortolotto, L.A. and Lorenzi-Filho, G. (2013) Effects of OSA Treatment on BP in Patients with Resistant Hypertension: A Randomized Trial. CHEST Journal, 144, 1487. http://dx.doi.org/10.1378/chest.13-0085

[46] Takase, B., Akim, T., Uehata, A., Ohsuza, M. and Kurita, A. (2004) Effect of Chronic Stress and Sleep Deprivation on Both Flow-Mediation Dilation in the Brachial Artery and the Intracellular Magnesium Level in Humans. Clinical Cardiology, 27, 223-227. http://dx.doi.org/10.1002/clc.4960270411

[47] Portaluppi, F., Cortelli, P., Avoni, P., Vergnani, L., Contin, M., Maltoni, P., Pavani, A., Sforza, E., degli Uberti, E.C. and Gambetti, P. (1994) Diurnal Blood Pressure Variation and Hormonal Correlates in Fatal Familial Insomnia. Hypertension, 23, 569-576. http://dx.doi.org/10.1161/01.HYP.23.5.569

[48] Fernandez-Mendoza, J., Vgontzas, A.N., Liao, D., Shaffer, M.L., Vela-Bueno, A., Basta, M. and Bixler, E.O. (2010) Insomnia with Objective Short Sleep Duration and Incident Hypertension: The Penn State Cohort. Hypertension, 60, 929-935. http://dx.doi.org/10.1161/HYPERTENSIONAHA.112.193268

[49] Almeida, O.P., Alfonso, H., Yeap, B.B., Hankey, G. and Flicker, L. (2011) Complaints of Difficulty to Fall Asleep Increase the Risk of Depression in Later Life: The Health in Men Study. Journal of Affective Disorders, 134, 208-216. http://dx.doi.org/10.1016/j.jad.2011.05.045

[50] Weber, M.A. (1990) Documentation of the Effective Length of Action of Antihypertensive Treatment. The American Journal of Cardiology, 66, 43C-48C. http://dx.doi.org/10.1016/0002-9149(90)90763-Q 


\section{Acronyms}

$\mathrm{SH}=$ hypertension; BP = blood pressure; DSM = Diagnostic and Statistical Manual of Mental Disorders; SRQ 20 = Self-Report Questionnaire; SCID = Structured Clinical Interview for DSM-IV; HR = heart rate; SNS = Sympathetic nervous system; HPA = hypothalamus-pituitary-adrenal axis; RAA = renin, angiotensin, aldosterone system; $\mathrm{NE}=$ norepinephrine; $\mathrm{CSF}=$ cerebrospinal fluid; HAM-D = Hamilton Depression Rating Scale; CRF = corticotropin releasing factor; $\mathrm{ACTH}=$ adrenocorticotropic hormone; $\mathrm{BMI}=$ body mass index; $\mathrm{SBP}=$ systolic blood pressure; $\mathrm{DBP}=$ diastolic blood pressure; $\mathrm{t}=$ time. 